Syntax Literate: Jurnal Ilmiah Indonesia p-ISSN: 2541-0849

e-ISSN: 2548-1398

Vol. 5, No. 11, November 2020

\title{
UJI PENETRASI FITOSOM EKSTRAK ETANOL DAUN SEMBUNG SERTA UJI AKTIVITAS ANTIOKSIDAN DENGAN METODE DPPH
}

\author{
Nurohman Ikra, Mumpui Esti dan Rachmaniar Rachmat \\ Universitas Pancasila (UP) Jakarta, Indonesia \\ Email: Ikranurohman77@gmail.com, esti_mumpuni@yahoo.com,dan \\ rachmaniarr@yahoo.com
}

\section{Abstract}

Phytosome is a delivery system formed by natural active ingredients and phosphatidylcholine. Phytosomes are used to increase the bioavailability of active ingredients. The active component with a too high polarity cannot pass through the lipid barrier of the skin or digestive system, so it cannot be absorbed. Flavonoids in the Blumea balsamifera L.DC have broad therapeutic potentials, one of which it is as an antioxidant. The phenolic compounds present in flavonoids have high polarity, causing low bioavailability. This study aims to make fitosome of the ethanol extracts of Blumea balsamifera L.DC, which have better penetration and antioxidant activity than the ethanol extracts of Blumea balsamifera L.DC itself. This method used was the antioxidant activity test between the ethanol extract of Blumea balsamifera (L.) DC. and the phytosome preparation of ethanol extract Blumea balsamifera (L.) DC, as well as a penetration test by calculating the diffusion profile of the extract ethanol and phytosomes. The results of this study showed that $70 \%$ ethanol extract of Blumea balsamifera L.DC can be made into phytosomes with a ratio of 1: 1 between the extracts and soy lechitin as phosphatidylcholine by using the lyophilization method (Freeze drying). Penetration of the phytosomes from the $70 \%$ ethanol extract of Blumea balsamifera L.DC. had increased when observing the total flavonoid levels. The shape of the phytosome has a higher average value of $5.03 \pm 1.64 \mu \mathrm{g} / \mathrm{g}$ than the extract form which is $2.56 \pm 1.23 \mu \mathrm{g} / \mathrm{g}$. The antioxidant activity of the $70 \%$ ethanol extract of Blumea balsamifera L.DC. was higher with an IC50 value of $53.01 \mu \mathrm{g} / \mathrm{mL}$ compared to phytosomes from the $70 \%$ ethanol extract Blumea balsamifera L.DC. with an IC50 value of $78.05 \mu \mathrm{g} / \mathrm{mL}$.

Keywords: Ethanol Extract of Blumea balsamifera L. DC; Phytosome; Penetration, Antioxidant

\begin{abstract}
Abstrak
Fitosom merupakan suatu sistem penghantaran yang dibentuk oleh bahan aktif alami dan fosfatidilkolin. Fitosom digunakan untuk meningkatkan bioavailabilitas bahan aktif. Komponen aktif dengan polaritas terlalu tinggi tidak dapat melewati penghalang lipid (lipid barrier) pada kulit atau sistem pencernaan, sehingga tidak dapat diserap. Flavonoid dalam daun sembung memiliki potensial terapetik yang luas, salah satunya adalah sebagai antioksidan, senyawa fenolik yang ada dalam flavonoid memiliki polaritas yang tinggi sehingga menyebabkan Bioavailabilitas
\end{abstract}


rendah. Penelitian ini bertujuan untuk membuat fitosom ekstrak etanol daun sembung (Blumea balsamifera (L) DC.) yang memiliki penetrasi dan aktivitas antioksidan yang lebih baik dari ekstrak etanol daun sembung. Metode pengujian yang dilakukan yaitu uji aktivitas antioksidan antara ekstrak etanol daun Sembung (Blumea balsamifera (L.) DC) dan sediaan phytosome ekstrak etanol daun Sembung (Blumea balsamifera (L.) DC), Serta dilakukan uji penetrasi dengan cara menghitung profil difusi dari ekstrak etanol daun sembung dan fitosom daun sembung. Hasil dari penelitian ini didapatkan ekstrak etanol $70 \%$ daun sembung (Blumea balsamifera (L) DC.) dapat di buat menjadi Fitosom dengan perbandingan 1:1 antara ekstrak dan soy lechitin sebagai fosfatidilkolin menggunakan metode liofilisasi (Freeze drying). Penetrasi dari fitosom Ekstrak etanol $70 \%$ daun sembung meningkat dengan melihat kadar flavonoid total. Bentuk fitosom memiliki nilai kadar rata-rata lebih tinggi yaitu 5,03 $\pm 1,64 \mu \mathrm{g} / \mathrm{g}$ dibanding bentuk ekstrak yaitu 2,56 $\pm 1,23 \mu \mathrm{g} / \mathrm{g}$. Aktivitas antioksidan dari ekstrak etanol $70 \%$ daun sembung (Blumea balsamifera (L) DC.) lebih tinggi dengan nilai IC50 53,01 $\mu \mathrm{g} / \mathrm{mL}$ dibandingkan fitosom ekstrak etanol 70\% daun sembung dengan nilai IC50 $78,05 \mu \mathrm{g} / \mathrm{m}$.

Kata kunci: Daun Sembung (Blumea Balsamifera (L) DC); Fitosom; Penetrasi; Antioksidan

\section{Pendahuluan}

Indonesia adalah Negara dengan kekayaan alam yang melimpah baik hewani maupun nabati. Tersebarnya kekayaan alam di Indonesia baik di daratan maupun lautan memberikan peluang bagi masyarakat Indonesia untuk memafaatkan sumber daya alam Indonesia. Penggunaan tanaman sebagai bahan yang bisa digunakan dalam bidang pengobatan dapat memberikan peluang untuk mendapatkan obat yang terjangkau secara ekonomis. Pemanfaatan tumbuhan dalam bidang pengobatan sudah populer dari masa ke masa, seperti halnya di Indonesia yang sudah mengenal jamu sejak zaman dahulu. Hal ini membuktikan bahwa alam, khususnya tumbuhan dapat dijadikan suatu sumber pengobatan yang alami dan mudah diperoleh (A, 2014).

Salah satu tumbuhan yang dimanfaatan dalam pengobatan di Indonesia adalah daun Sembung (Blumea Balsamifera L. DC). daun sembung memiliki kandungan zat aktif yaitu minyak atsiri 0,5\% (berupa sineol, borneol, landerol, dan kamper), flavanoid, tanin, damar, dan ksantoksilin (Yuan et al., 2016). Beberapa khasiat yang diketahui dari daun sembung diantaranya untuk mengobati beri-beri, eksim, sakit pinggang, dermatitis, rematik, cedera kulit (Pang et al., 2014), antimikroba, antiinflamasi (Nessa, Ismail, \& Mohamed, 2010). penyembuhan luka dan antioksidan (Saewan, Koysomboon, \& Chantrapromma, 2011).

Flavonoid memiliki potensial terapetik yang luas, senyawa fenolik yang ada dalam flavonoid memiliki polaritas yang tinggi sehingga menyebabkan Bioavailabilitas rendah (Singh, Saharan, Singh, \& Bhandari, 2011). Salah satu cara untuk memperbaiki bioavailabilitas yaitu dengan menerapkan teknologi fitosom pada ekstrak daun sembung (Freag, Elnaggar, \& Abdallah, 2013). 
Fitosom merupakan suatu sistem penghantaran yang dibentuk oleh bahan aktif alami dan fosfatidilkolin (Gandhi, Dutta, Pal, \& Bakshi, 2012). Fitosom digunakan untuk meningkatkan bioavailabilitas bahan aktif. Komponen aktif dengan polaritas terlalu tinggi tidak dapat melewati penghalang lipid (lipid barrier) pada kulit atau sistem pencernaan, sehingga tidak dapat diserap (Saha, Sarma, Saikia, \& Chakrabarty, 2013). Fitosom membantu mengurangi polaritas zat aktif, sehingga membuatnya lebih mudah diserap (Singh et al., 2011).

Melihat potensi Sembung (Blumea balsamifera (L) DC.) sebagai antioksidan, dan belum pernah dilakukan penelitian tentang pembuatan fitosom dari daun sembung, maka dilakukan penelitian untuk membuat fitosom ekstrak daun sembung yang diharapkan dapat membantu mengoptimalkan penetrasi dan bioaktivitas untuk memaksimalkan aktivitas senyawa tersebut.

\section{Metode Penelitian}

Metode yang digunakan dalam penelitian ini dilakukan secara kuantitatif yaitu dengan melihat nilai $\mathrm{IC}_{50}$ dan profil difusi dari ekstrak etanol daun sembung dan fitosom ekstrak daun sembung. Bahan utama yang digunakan untuk penelitian ini adalah Daun Sembung muda (Blumea balsamifera (L) DC.) yang diperoleh dari area perkebunan Sukarapih, Kuningan Jawa Barat. Kemudian dilakukan determinasi di Laboratorium Identifikasi dan Determinasi ITB. pembuatan ekstrak dengan menggunakan ekstrak etanol 70\%, Setelah didapatkan ekstrak kemudian dilakukan pengujian mutu ekstrak daun sembung meliputi kadar sari larut air, kadar abu dan kadar air. Ekstrak yang di peroleh selanjutnya dibuat fitosom, Pada saat proses pencampuran larutan ekstrak dengan larutan Soy lecithin di lakukan secara perlahan setetes demi setetes sambil berlangsungnya proses stirring hal ini bertujuan untuk mendapatkan kompleks senyawa yang homogen dan stabil. Proses stirring di lakukan dengan kecepatan $700 \mathrm{rpm}$ selama $3 \mathrm{jam}$. Aquadest dipilih sebagai sebagai pelarut karena untuk memudahkan proses liofilisasi, sebab aquadest lebih mudah mengalami proses pembekuan dengan demikian dapat mengurangi kemungkinan terjadinya bumping atau terbuangnya cairan karna tekanan oleh vakum pada saat proses liofilisasi (freeze drying). Dilakukan karakterisasi fitosom untuk melihat fitosom yang terbentuk memenuhi standar yaitu ukuran partikel dan indeks polidisperitas, zeta potensial, morfologi eksternal dan identifikasi senyawa. Dari fitosom yang terbentuk kemudian dilakukan uji aktivitas anti oksidan dengan uji difusi untuk melihat setelah dibuat fitosom apakah terdapat perbedaan yang signifikan disbanding bentuk ekstraknya yaitu dengan melihat nilai $\mathrm{IC}_{50}$ dan profil difusi dari ekstrak etanol daun sembung dan fitosom ekstrak daun sembung. 


\section{Hasil dan Pembahasan}

\section{A. Determinasi Tanaman}

Hasil determinasi daun sembung yang diteliti di Sekolah Ilmu dan Teknologi Hayati Institut Teknologi Bandung (SITH-ITB) Bandung menunjukkan bahwa tanaman yanng digunakan dalam penelitian ini adalah daun Sembung (Blumea balsamifera (L) DC.)

\section{B. Pembuatan ekstrak}

Hasil dapat dilihat pada tabel 1 berikut:

Tabel 1

Pemeriksaan Ekstrak Daun Sembung

\begin{tabular}{ccc}
\hline Pemeriksaan & Hasil Pemeriksaan & Keterangan \\
\hline Hasil rendemen $(\%)$ & Bobot simplisia $(\mathrm{g})$ & 250 \\
\cline { 2 - 3 } & $\begin{array}{c}\text { Jumlah ekstrak kental } \\
(\mathrm{g})\end{array}$ & 8,3 \\
\cline { 2 - 3 } & DER- native & 30,12 \\
\cline { 2 - 3 } & Rendemen $(\%)$ & 3,32 \\
\hline
\end{tabular}

Berdasarkan hasil maserat yang diperoleh dalam bentuk cair berwarna hijau tua yang berbau khas daun sembung. kemudian dari 250gram daun sembung yang dipekatkan diperoleh ekstrak etanol kental daun sembung sejumlah 8,3gram dengan DER-native sejumlah 30,12 dan rendeman sebesar 3,32\%. Dari hasil tersebut diketahui bahwa sebanyak 250gram simplisia daun sembung dapat menghasilkan 30,12gram ekstrak atau 3,32\% dari bobot simplisia yang diekstraksi.

\section{Pengujian Mutu Ekstrak}

Tabel 2

Hasil Pengujian Mutu Ekstrak

\begin{tabular}{llc}
\hline \multicolumn{1}{c}{ Parameter } & Hasil uji (\%) & Hasil rata-rata \\
\cline { 1 - 2 } Kadar sari larut air & 17,86 & $18,68 \% \pm 0,81$ \\
\cline { 1 - 2 } Kadar air & 19,49 & $8,41 \% \pm 0,38$ \\
\cline { 1 - 2 } Kadar abu total & 8,02 & \multirow{2}{*}{$1,89 \% \pm 0,17$} \\
\hline
\end{tabular}

Hasil pengujian parameter mutu nonspesifik di atas menunjukkan kadar air dengan menggunakan metode karl fischer pada ekstrak daun sembung yaitu 8,41\% telah memenuhi persyaratan Peraturan BPOM tentang persyaratan mutu obat tradisional kadar air untuk ekstrak adalah $\leq 10 \%$. Kadar air dalam ekstrak harus memenuhi syarat karena kadar air yang besar dapat menjadi media yang baik untuk pertumbuhan mikroba. Hasil total kadar abu dapat menunjukkan total mineral yang terkandung dalam ekstrak daun sembung. Bahan-bahan organik $(\mathrm{Hg}, \mathrm{Pb}$, Silikat, $\mathrm{K}, \mathrm{Mg}, \mathrm{Ca}$ ) dalam proses pembakaran akan terbakar, tetapi komponen anorganiknya tidak terbakar dan sebab itu disebut sebagai abu. Total kadar abu dalam ekstrak 
daun sembung adalah $1,89 \%$. Hasil uji parameter di atas memenuhi persyaratan Depkes RI 2008 yaitu tidak lebih dari 16,6\%.

\section{Karakterisasi Fitosom}

Tabel 3

Hasil pengukuran partikel dan indeks polidisperitas

\begin{tabular}{llll}
\hline Sampel uji & Pengulangan & \multicolumn{1}{c}{$\begin{array}{c}\text { Ukuran Partikel } \\
(\mathbf{n m})\end{array}$} & $\begin{array}{c}\text { Indeks } \\
\text { Polidisperitas }\end{array}$ \\
\hline \multirow{2}{*}{$\begin{array}{l}\text { Ekstrak } \\
\text { daun } \\
\text { sembung }\end{array}$} & 1 & 1238 & 0,653 \\
\cline { 2 - 4 } & 2 & 1284 & 0,671 \\
\cline { 2 - 4 } & 3 & 1253 & 0,615 \\
\hline Fitosom & Rata-rata & 1258 & 0,646 \\
\cline { 2 - 4 } & 1 & 592,8 & 0,295 \\
\cline { 2 - 4 } & 2 & 572,9 & 0,304 \\
\cline { 2 - 4 } & Rata-rata & 563,9 & 0,369 \\
\hline
\end{tabular}

Berdasarkan hasil terlihat bahwa fitosom memiliki ukuran partikel dan indeks polidisperitas lebih kecil yaitu 576,5 nm, 0,322 dibandingkan ekstrak daun sembung sebesar $1258 \mathrm{~nm}, 0,646$. Ukuran fitosom yang diperoleh memenuhi persyaratan nanopartikel dan termasuk kategori fine particles $(100-2500 \mathrm{~nm})$ (Mishra \& Tiwari, 2013).

Tabel 4

Hasil pengukuran zeta potensial

\begin{tabular}{ll}
\hline \multicolumn{1}{c}{ Sampel uji } & \multicolumn{1}{c}{ Zeta potensial $(\mathbf{m V})$} \\
\hline Ekstrak etanol daun sembung & $-12,1$ \\
\hline $\begin{array}{l}\text { Fitosom ekstrak etanol daun } \\
\text { sembung }\end{array}$ & $-51,5$ \\
\hline
\end{tabular}

Penelitian ini menghasilkan nilai zeta potensial negatif dari ekstrak daun sembung dan fitosom ekstrak daun sembung yang telah dibuat yaitu -12,1 dan 51,5. Nilai zeta potensial negatif dapat disebabkan karena terdapat ekstrak etanol 70\% memiliki muatan negatif, kemungkinan lainnya adalah karena kurangnya kecepatan pada saat pengadukan menggunakan magnetik stirer, karena semakin tinggi kecepatan pengadukan maka banyak partikel yang terpecah menjadi partikel berukuran nano, selain itu peningkatan lama pengadukan akan memperbesar intensitas molekul pelarut untuk bersentuhan dengan soy lechitin sehingga ukuran partikel yang dihasilkan semakin kecil (Stiehl, Baran, Ho, \& Marciniak-Czochra, 2014). Nilai zeta potensial yang dihasilkan pada penelitian ini dianggap tidak baik karena tidak lebih dari $+30 \mathrm{mV}$ dan tidak kurang dari -30 mV (Murdock, BraydichStolle, Schrand, Schlager, \& Hussain, 2008). 

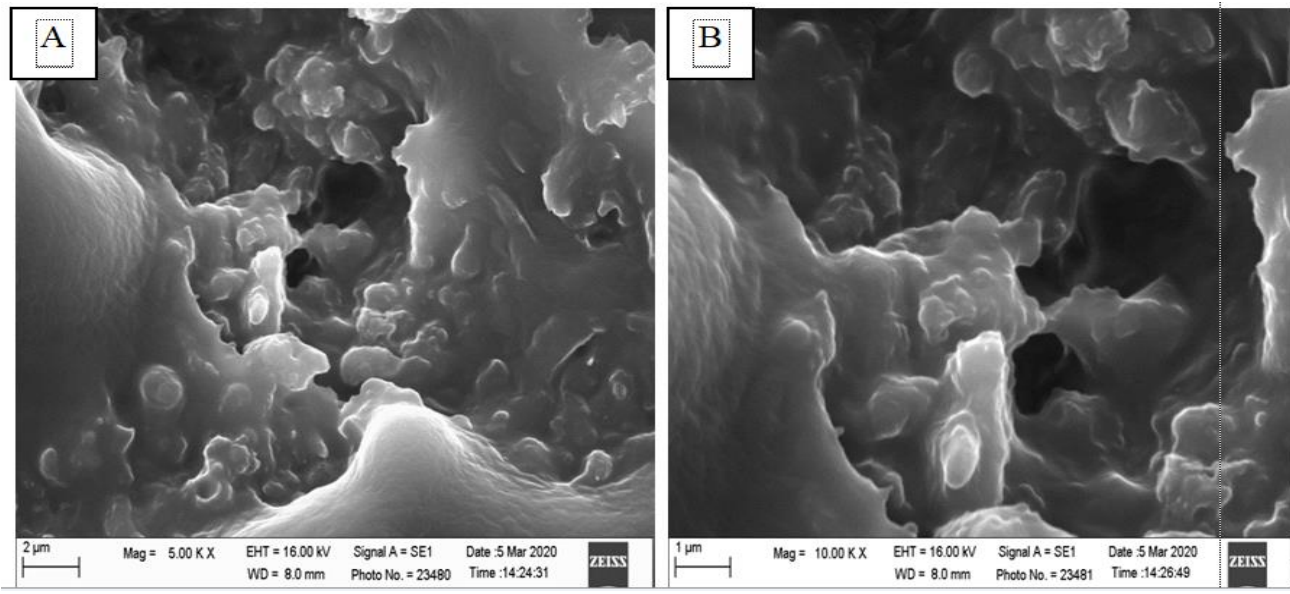

\section{Gambar 1}

\section{Hasil pengamatan morfologi eksternal}

Berdasarkan hasil pada masing-masing pembesaran didapatkan morfologi fitosom yang kurang sferis, bentuk partikel yang kurang sferis dapat mempermudah interaksi antarpartikel sehingga terjadi agregasi yang mengakibatkan ukuran partikel semakin besar (Prasetiowati, Prasetya, \& Wardani, 2018). Hal ini bisa disebabkan juga karena kurang besarnya kecepatan (rpm) atau kurang lamanya waktu pembentukan kompleks pada saat proses stirring sehingga pada saat pembentukan kompleks fitosom ukuran partikel yang terbentuk tidak seragam (Stiehl et al., 2014).

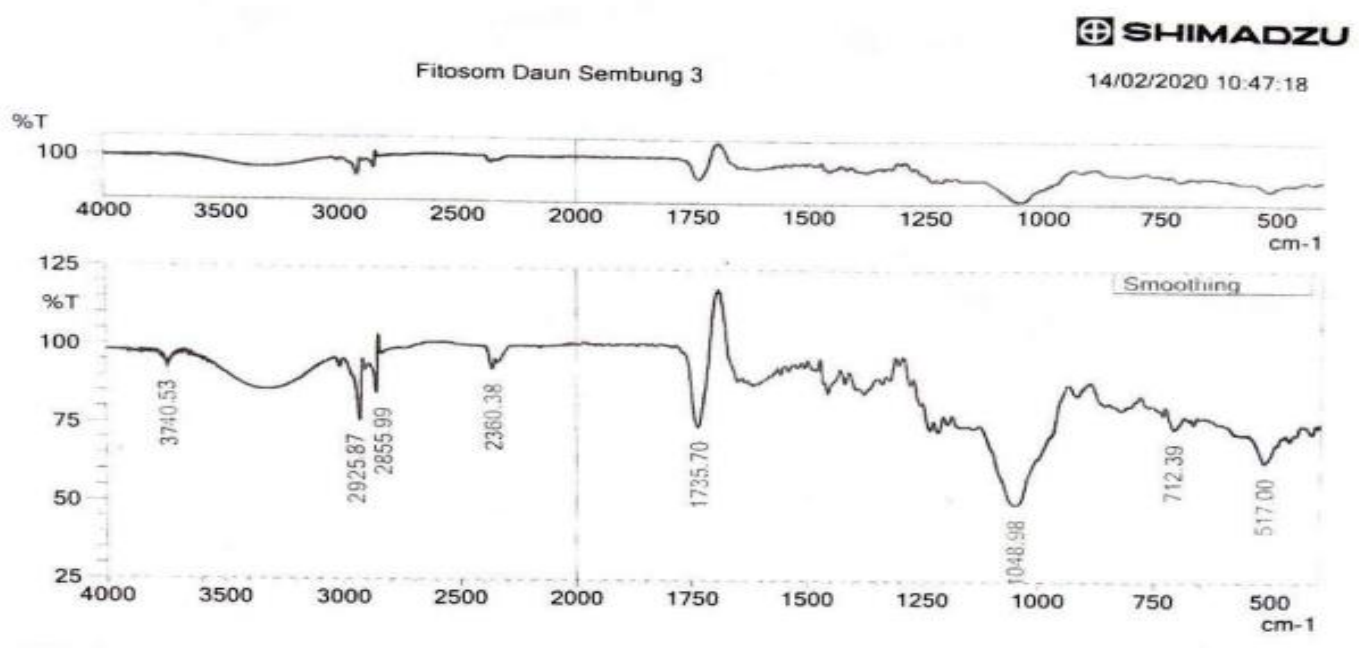

Gambar 2

Hasil identifikasi senyawa menggunakan Spektrofotometri FTIR 
Tabel 5

\begin{tabular}{l|l|l|l|l}
\multicolumn{5}{c}{ Hasil pemeriksaan Spektrofotometri FTIR } \\
\hline Sampel & $\begin{array}{l}\text { Frekuensi } \\
\left(\mathbf{c m}^{-1}\right)\end{array}$ & $\begin{array}{l}\text { Rentang } \\
\text { Frekuensi } \\
\left(\mathbf{c m}^{-\mathbf{1}}\right)\end{array}$ & $\begin{array}{l}\text { Jenis } \\
\text { Ikatan }\end{array}$ & $\begin{array}{l}\text { Jenis } \\
\text { Senyawa }\end{array}$ \\
\hline \multirow{2}{*}{$\begin{array}{l}\text { Fitosom ekstrak } \\
\text { etanol daun } \\
\text { sembung }\end{array}$} & 3740,53 & $3750-3000$ & O-H & Hindroksil \\
\cline { 2 - 6 } & 2925,87 & $2853-2962$ & C-H & Alkana \\
\cline { 2 - 6 } & 1735,70 & $1750-1650$ & C=O & Karbonil \\
\cline { 2 - 6 } & 1048,98 & $1300-1000$ & C-O & Karboksil \\
\hline
\end{tabular}

Hasil spektrum IR menunjukkan terdapat beberapa gugus fungsional pada pita-pita serapan. Pada rentang frekuensi 3000-3750 $\mathrm{cm}^{-1}$ didapatkan pita yang tajam, rentang frekuensi tersebut merupakan karakteristik senyawa fenolik $(-\mathrm{OH})$ hal ini disebabkan karena daun sembung mengandung flavonoid, pada rentang $2853-2962 \mathrm{~cm}^{-1}$ diperoleh adanya gugus alkana $(\mathrm{C}-\mathrm{H})$, pada rentang $1750-1650 \mathrm{~cm}^{-}$ 1 diperoleh adanya gugus karbonil $(\mathrm{C}=\mathrm{O})$, dan pada rentang $1000-1300 \mathrm{~cm}^{-1}$ diperoleh adanya gugus karboksil(C-O) (Baran N, 2014).

E. Uji Difusi

Tabel 6

Hasil serapan baku banding quarsetin

\begin{tabular}{cc}
\hline $\begin{array}{c}\text { Konsentrasi } \\
(\boldsymbol{\mu g} / \mathbf{m L})\end{array}$ & Serapan \\
\hline 0,5005 & 0,0255 \\
\hline 1,0010 & 0,0575 \\
\hline 2,0020 & 0,1022 \\
\hline 5,0050 & 0,2558 \\
\hline 10,0100 & 0,473 \\
\hline 15,0150 & 0,7987 \\
\hline 20,0200 & 1,0945 \\
\hline
\end{tabular}

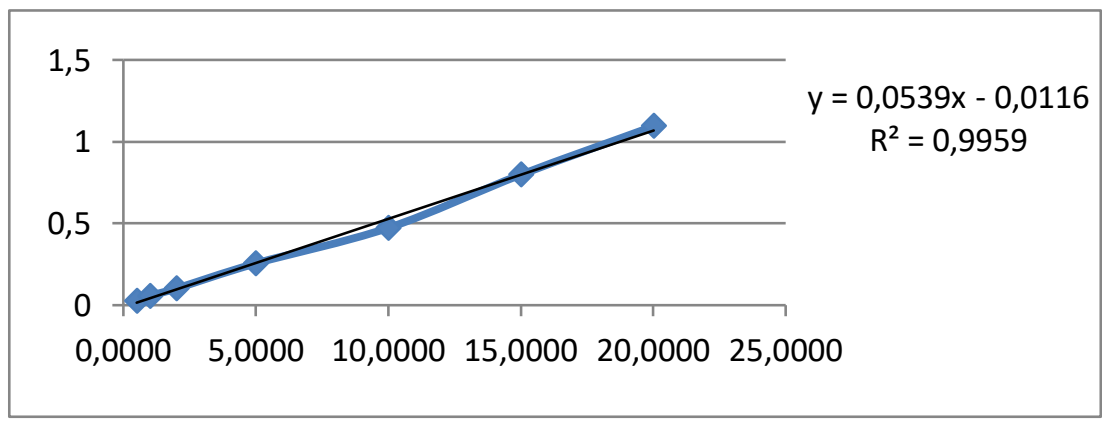

Gambar 3

Kurva kalibrasi quarsetin

Berdasarkan hasil pengukuran BP quarsetin menggunakan spektrofotometri UV-VIS pada panjang gelombang $373 \mathrm{~nm}$, maka di dapatkan persamaan kurva baku 
quarsetin yaitu $\mathrm{y}=0,0539 \mathrm{x}-0,0116$. Persamaan regresi yang didapatkan dapat digunakan untuk menetapkan kadar flavonoid total dalam sampel.

\section{Tabel 7}

Hasil serapan sampel uji

\begin{tabular}{|c|c|c|c|c|}
\hline Sampel & Serapan & $\begin{array}{c}\text { Konsentrasi } \\
\text { terbaca } \\
(\mu \mathrm{g} / \mathrm{mL})\end{array}$ & $\begin{array}{c}\text { Kadar dalam } \\
\text { sampel } \\
(\mu \mathrm{g} / \mathrm{g})\end{array}$ & $\begin{array}{l}\text { Rata-rata } \\
(\mu \mathrm{g} / \mathrm{g})\end{array}$ \\
\hline $\begin{array}{c}\text { Ekstrak etanol daun } \\
\text { sembung ulangan ke } 1\end{array}$ & 0,0025 & 0,2613 & 1,3162 & \multirow{3}{*}{$2,56 \pm 1,23$} \\
\hline $\begin{array}{c}\text { Ekstrak etanol daun } \\
\text { sembung ulangan ke } 2\end{array}$ & 0,0152 & 0,4968 & 2,5869 & \\
\hline $\begin{array}{c}\text { Ekstrak etanol daun } \\
\text { sembung ulangan ke } 3\end{array}$ & 0,0293 & 0,7582 & 3,7790 & \\
\hline $\begin{array}{l}\text { Fitosom ekstrak etanol } \\
\text { daun sembung ulangan } \\
\text { ke } 1\end{array}$ & 0,0321 & 0,8101 & 4,0604 & \multirow{3}{*}{$5,03 \pm 1,64$} \\
\hline $\begin{array}{l}\text { Fitosom ekstrak etanol } \\
\text { daun sembung ulangan } \\
\text { ke } 2\end{array}$ & 0,0631 & 1,3849 & 7,0185 & \\
\hline $\begin{array}{l}\text { Fitosom ekstrak etanol } \\
\text { daun sembung ulangan } \\
\text { ke } 3\end{array}$ & 0,0327 & 0,8213 & 4,0997 & \\
\hline
\end{tabular}

Berdasarkan hasil yang diperoleh dari uji sel difusi franz selama 60 menit didapatkan hasil rata-rata kadar flavonoid total pada ekstrak etanol 70\% daun sembung yaitu $2,56 \pm 1,23 \mu \mathrm{g} / \mathrm{g}$, sedangkan pada sampel fitosom ekstrak etanol $70 \%$ daun sembung diperoleh hasil kadar rata-rata flavonoid total yaitu 5,03 $\pm 1,64$ $\mu \mathrm{g} / \mathrm{g}$. Hal ini berarti fitosom dapat meningkatkan penetrasi zat aktif yang memiliki polaritas yang tinggi. Untuk melihat perbedaan profil difusi maka dilakukan uji statistik menggunakan program SPSS. Terlebih dahulu dilakukan uji normalitas data untuk menentukan uji yang digunakan apakah parametrik atau non parametrik, hasil uji normalitas menunjukan bahwa ekstrak etanol $70 \%$ daun sembung berdistribusi normal dengan nilai $\mathrm{p}=0,964(>0,05)$, sedangkan pada fitosom ekstrak etanol $70 \%$ daun sembung tidak berdistribusi normal dengan nilai $\mathrm{p}=0,022$ $(<0,05)$, karena salah satu data tidak berdistribusi normal maka dilakukan uji non parametrik dengan menggunakan Mann-Whitney Test. Hasil uji menunjukan bahwa terdapat perbedaan profil difusi (kadar flavonoid total) antara kelompok perlakuan bentuk ekstrak dan kelompok perlakuan bentuk fitosom dengan nilai $\mathrm{p}=0,05$, hal ini menunjukan bahwa fitosom mempunyai pengaruh untuk meningkatkan bioavailabilitas dengan melihat kadar flavonoid total dengan metode sel difusi franz. 


\section{F. Uji aktivitas antioksidan}

\section{Tabel 8}

Uji aktivitas antioksidan

\begin{tabular}{lcc}
\hline \multicolumn{3}{c}{ Hasil Uji Antioksidan } \\
\hline Sampel & IC 50 $(\mu \mathrm{g} / \mathrm{mL})$ & IC50 Rata-Rata $(\mu \mathrm{g} / \mathrm{mL})$ \\
\hline Vitamin C Ulangan 1 & 6,96 & \multirow{2}{*}{$7,00 \pm 0,04$} \\
\hline Vitamin C Ulangan 2 & 7,03 & \\
\cline { 1 - 2 } Ekstrak Etanol Ulangan 1 & 54,25 & \multirow{2}{*}{$53,01 \pm 0,96$} \\
\cline { 1 - 2 } Ekstrak Etanol Ulangan 2 & 51,92 & \\
\cline { 1 - 2 } Ekstrak Etanol Ulangan 3 & 52,86 & \\
\cline { 1 - 2 } Fitosom Ulangan 1 & 79,19 & $78,05 \pm 0,94$ \\
\hline Fitosom Ulangan 2 & 76,99 & \\
\hline Fitosom Ulangan 3 & 77,96 &
\end{tabular}

Hasil menunjukkan bahwa vit $\mathrm{C}$ memiliki aktivita antioksidan yang sangat kuat (syarat $<50 \mu \mathrm{g} / \mathrm{mL}$ ), fitosom ekstrak Etanol $70 \%$ daun sembung memiliki aktivitas antioksidan kuat (syarat 50-100 $\mu \mathrm{g} / \mathrm{mL}$ ) memiliki aktivitas lebih kecil bila dibandingkan dengan hasil antioksidan ekstrak etanol $70 \%$ daun sembung, untuk melihat perbedaan aktivitas antioksidan maka dilakukan uji statistik menggunakan program SPSS. Terlebih dahulu dilakukan uji normalitas data untuk menentukan uji yang digunakan apakah parametrik atau non parametrik, hasil uji normalitas menunjukan bahwa ekstrak etanol $70 \%$ daun sembung berdistribusi normal dengan nilai $\mathrm{p}=0,788(>0,05)$, sedangkan pada fitosom ekstrak etanol $70 \%$ daun sembung tidak berdistribusi normal dengan nilai $\mathrm{p}=0,049(<0,05)$, karena salah satu data tidak berdistribusi normal maka dilakukan uji non parametrik dengan menggunakan Mann-Whitney Test. Hasil uji menunjukan bahwa terdapat perbedaan antioksidan antara kelompok perlakuan bentuk ekstrak dan kelompok perlakuan bentuk fitosom dengan nilai $\mathrm{p}=0,05$. Hal ini terjadi bisa dikarenakan kompleks yang terbentuk tidak sempurna yang mengakibatkan tidak bisa meredam DPPH dengan maksimal.

\section{Kesimpulan}

Ekstrak etanol 70\% daun sembung (Blumea balsamifera (L) DC.) dapat di buat menjadi Fitosom menggunakan metode liofilisasi (Freeze drying) dengan menggunakan Soy lecithin sebagai fosfolipid. Penetrasi dari fitosom Ekstrak etanol $70 \%$ daun sembung meningkat dengan melihat kadar flavonoid total. Bentuk fitosom memiliki nilai kadar rata-rata lebih tinggi yaitu 5,03 $\pm 1,64 \mu \mathrm{g} / \mathrm{g}$ dibanding bentuk ekstrak yaitu $2,56 \pm 1,23 \mu \mathrm{g} / \mathrm{g}$. Aktivitas antioksidan dari ekstrak etanol $70 \%$ daun sembung (Blumea balsamifera (L) DC.) lebih tinggi dengan nilai IC50 53,01 $\mu \mathrm{g} / \mathrm{mL}$ dibandingkan fitosom ekstrak etanol 70\% daun sembung dengan nilai IC50 78,05 $\mu \mathrm{g} / \mathrm{mL}$. 


\section{BIBLIOGRAFI}

A, Hariana. (2014). Tumbuhan Obat dan Khasiatnya (3rd ed). Jakarta: Penebar Swadaya.

Freag, May S., Elnaggar, Yosra S. R., \& Abdallah, Ossama Y. (2013). Lyophilized phytosomal nanocarriers as platforms for enhanced diosmin delivery: optimization and ex vivo permeation. International Journal of Nanomedicine, 8, 2385.

Gandhi, Arijit, Dutta, Avik, Pal, Avijit, \& Bakshi, Paromita. (2012). Recent trends of phytosomes for delivering herbal extract with improved bioavailability. Journal of Pharmacognosy and Phytochemistry, 1(4), 6-14.

Mishra, R. K., \& Tiwari, G. N. (2013). Energy and exergy analysis of hybrid photovoltaic thermal water collector for constant collection temperature mode. Solar Energy, 90, 58-67.

Murdock, Richard C., Braydich-Stolle, Laura, Schrand, Amanda M., Schlager, John J., \& Hussain, Saber M. (2008). Characterization of nanomaterial dispersion in solution prior to in vitro exposure using dynamic light scattering technique. Toxicological Sciences, 101(2), 239-253.

Nessa, Fazilatun, Ismail, Zhari, \& Mohamed, Nornisah. (2010). Xanthine oxidase inhibitory activities of extracts and flavonoids of the leaves of Blumea balsamifera. Pharmaceutical Biology, 48(12), 1405-1412.

Pang, Yuxin, Wang, Dan, Fan, Zuowang, Chen, Xiaolu, Yu, Fulai, Hu, Xuan, Wang, Kai, \& Yuan, Lei. (2014). Blumea balsamifera-A phytochemical and pharmacological review. Molecules, 19(7), 9453-9477.

Prasetiowati, Andi Lana, Prasetya, Agung Tri, \& Wardani, Sri. (2018). Sintesis Nanopartikel Perak dengan Bioreduktor Ekstrak Daun Belimbing Wuluh (Averrhoa bilimbi L.) Uji Aktivitasnya sebagai Antibakteri. Indonesian Journal of Chemical Science, 7(2), 160-166.

Saewan, N., Koysomboon, S., \& Chantrapromma, K. (2011). Anti-tyrosinase and anticancer activities of flavonoids from Blumea balsamifera DC. Journal of Medicinal Plants Research, 5(6), 1018-1025.

Saha, Sanjay, Sarma, Anupam, Saikia, Pranjal, \& Chakrabarty, T. (2013). Phytosome: A brief overview. Scholars Academic Journal of Pharmacy, 2(1), 12-20.

Singh, Anupama, Saharan, Vikas Anand, Singh, Manjeet, \& Bhandari, Anil. (2011). Phytosome: drug delivery system for polyphenolic phytoconstituents. Iranian Journal of Pharmaceutical Sciences, 7(4), 209-219.

Stiehl, Thomas, Baran, Natalia, Ho, Anthony D., \& Marciniak-Czochra, Anna. (2014). Clonal selection and therapy resistance in acute leukaemias: mathematical modelling explains different proliferation patterns at diagnosis and relapse. Journal of The Royal Society Interface, 11(94), 20140079.

Yuan, Yuan, Huang, Mei, Pang, Yu Xin, Yu, Fu Lai, Chen, Ce, Liu, Li Wei, Chen, 
Uji Penetrasi Fitosom Ekstrak Etanol Daun Sembung Serta Uji Aktivitas Antioksidan Dengan Metode Dpph

Zhen Xia, Zhang, Ying Bo, Chen, Xiao Lu, \& Hu, Xuan. (2016). Variations in essential oil yield, composition, and antioxidant activity of different plant organs from Blumea balsamifera (L.) DC. at different growth times. Molecules, 21(8), 1024. 